\section{Estrategias para cazar al consumidor del nuevo siglo}

\author{
Salvador Carrillo
}

os cambios en las estrategias de $\leftarrow$ medios han ido aparejados a los cambios en el comportamiento del consumidor y a la aparición de nuevos medios. Cambios sociales como el incremento de mujeres que trabajan, el incremento de padres solteros, como el de personas que optan por vivir solas; cambios en los estilos de vida de las personas de la tercera edad, etcétera, implican también cambios en los hábitos de consumo de productos y medios.

Por otro lado, la fuerte competencia en donde muchos productos solo se diferencian en aspectos sutiles ha motivado la búsqueda de nuevas formas de comunicación para llegar con eficacia al consumidor. Los cambios se presentan no solamente en los países desarrollados con alta tecnología, sino también en países como el nuestro, que asimila la nueva tecnología y la utiliza debido a que somos parte de una economía globalizada, con gran presencia de productos que se comercializan en el ámbito mundial.

Años atrás, las marcas se publicitaban bajo el concepto de producto, orientando la comunicación a un público general; luego, ante una mayor competencia, se buscó la segmentación de los públicos; poco después se puso en práctica la teoría del posicionamiento, tratando de obtener un lugar destacado en la mente del consumidor. Paralelamente, se explotaron los nichos, que son subsegmentos con necesidades 
más especializadas. Actualmente se tiende a trabajar con el concepto de márketing directo, haciendo uso de una comunicación más personalizada y buscando a través de ella una relación más directa con el consumidor.

Estos cambios en los consumidores cada vez más individualistas al momento de escoger alguna alternativa de un producto o servicio de los muchos que le ofrece el mercado, y por otro lado la gran diversidad de canales de comunicación, muchos de ellos saturados de mensajes en un contexto de feroz competencia entre las marcas, lleva a una creciente indiferencia por parte del consumidor, con la consecuente pérdida de eficacia de los mensajes publicitarios. Esta situación ha hecho reflexionar a los anunciantes para decidirse por la utilización de medios que les permita una mayor interactividad con los consumidores, por lo que las agencias de publicidad se han visto exigidas a un nuevo tipo de creatividad para adecuarse a estos nuevos medios.

Al respecto, se están utilizando con mayor intensidad medios como el correo directo, que a diferencia de antes utiliza materiales de alta calidad, como el caso de los encartes que van adosados al diario y dirigidos a un público previamente seleccionado; el telemárketing (publicidad vía teléfono), que si bien es cierto es un medio altamente intrusivo, es eficaz en muchos casos por los buenos resultados obtenidos; la internet, que aun cuando también es un medio invasivo, como son los spam, se puede considerar un medio eficaz, especialmente en el correo electrónico y las páginas web, con mensajes bien enfocados y dirigidos a las personas del grupo objetivo.

Respecto de internet es interesante conocer la proyección que tiene su consumo los últimos años en la ciudad de Lima. Entre el 2002 y el 2004 su audiencia promedio diaria ha crecido 94 por ciento. Actualmente es utilizado semanalmente por el 24,5 de las personas de 11 años a más de todos los niveles socioeconómicos, gracias a la proliferación de las cabinas de internet.

La nueva tecnología está permitiendo un mejor impacto de algunos medios en el público, un ejemplo claro lo tenemos en la calidad de las imágenes en los paneles publicitarios, gracias al vinyl, elemento que desde hace unos pocos años permite presentar imágenes con la calidad de una fotografía. Este aspecto, aunado a una diversificación en los elementos de vía pública, han contribuido a una importante alza de las inversiones en este medio respecto de la década pasada.

Los actuales medios de comunicación, llámense televisión, radio o diarios, ya no funcionan como antes en cuanto a su poder de persuasión por varias razones tan obvias como la saturación de mensajes, el zapping y la 
gran cantidad de vehículos que presenta cada medio masivo, aspectos que han contribuido a una pérdida de eficacia. En otras palabras, las inversiones publicitarias en los medios masivos no están dando los resultados esperados en las ventas.

Sin embargo, de estos medios clásicos, la radio y la televisión están próximos a cambiar a través de la tecnología digital, que permitirá el acceso a miles de emisoras de todo el mundo. Este avance tecnológico requeriría el cambio de los receptores actuales, por lo que su desarrollo no es de corto plazo. Por otro lado, la radio satelital se ha adelantado y a través de servicios como Sirius y XM es posible llegar a todas las radios del mundo.

En lo que respecta a la televisión, la tecnología también ha puesto a disposición de los usuarios un servicio como el TIVO, que permite estructurar una programación al gusto del cliente, combinando los programas de diferentes canales de cable o de la televisión abierta en los horarios que desee el usuario.

La nueva tecnología está orientada a enlazar a la computadora con medios como la televisión, la radio y el teléfono, entre otros, permitiendo al consumidor una total independencia para escoger el medio y diseñar una mezcla de contenidos que lo hagan único en la combinación de sus preferencias, y, por lo tanto, diferente a los demás, casi como una huella dactilar. Con lo cual pasaríamos de una audiencia masiva a una audiencia atomizada.

Esta situación de buscar medios más personalizados ha determinado que los anunciantes comiencen a prestar más atención a medios más segmentados y de otro tipo, como los llamados medios below the line (BTL) (telemarketing, marketing promocional, correo directo, merchandising, etcétera), cuyas características consisten en llegar en forma directa no masiva a los consumidores en sus lugares habituales, como el hogar, el supermercado o un lugar de diversión: bar, discoteca, restaurante, playas, etcétera, buscando su respuesta directa.

Otra ventaja de los medios BTL es su gran adaptabilidad y flexibilidad para utilizarlos en diversos contextos y coberturas geográficas.

La siguiente información contenida en el cuadro de inversiones publicitarias muestra cómo en los últimos diez años los medios orientados hacia una comunicación más directa con el público han ido incrementando su participación, a pesar de los altibajos de las inversiones publicitarias debido a las crisis político-económicas que han golpeado nuestro país en la última década. 
Evolución de las inversiones publicitarias en los medios a tarifa real a nivel nacional 1995-2004

\begin{tabular}{ccccccccc}
\hline Años & $\begin{array}{c}\text { Millones } \\
\text { US } \$\end{array}$ & $\begin{array}{c}\text { TV } \\
\%\end{array}$ & $\begin{array}{c}\text { Diarios } \\
\%\end{array}$ & $\begin{array}{c}\text { Radios } \\
\%\end{array}$ & $\begin{array}{c}\text { Revistas } \\
\%\end{array}$ & $\begin{array}{c}\text { Vía pública } \\
\%\end{array}$ & $\begin{array}{c}\text { Cable } \\
\%\end{array}$ & $\begin{array}{c}\text { Otros } \\
\%\end{array}$ \\
\hline 1995 & 225 & 56,0 & 25,3 & 10,7 & 3,6 & 2,7 & -- & 1,7 \\
1996 & 265 & 58,1 & 22,3 & 9,8 & 3,0 & 4,9 & -- & 1,9 \\
1997 & 341 & 48,4 & 31,4 & 8,2 & 2,6 & 7,6 & -- & 1,8 \\
1998 & 302 & 43,7 & 31,1 & 9,3 & 2,6 & 10,6 & 1,0 & 1,7 \\
1999 & 239 & 40,2 & 31,4 & 11,7 & 2,5 & 10,4 & 2,5 & 1,3 \\
2000 & 205 & 38,5 & 32,2 & 12,2 & 2,4 & 9,8 & 2,9 & 2,0 \\
2001 & 192 & 32,8 & 32,8 & 12,5 & 2,6 & 12,0 & 4,7 & 2,6 \\
2002 & 196 & 35,2 & 30,6 & 11,7 & 2,6 & 11,2 & 5,6 & 3,1 \\
2003 & 201 & 36,8 & 28,4 & 11,4 & 2,5 & 11,9 & 5,5 & 3,5 \\
2004 & 216 & 37,0 & 26,9 & 12,0 & 2,8 & 12,0 & 5,6 & 3,7 \\
\hline
\end{tabular}

Fuente: Estimado por Compañía Peruana de Investigación de Mercados (CPI).

El volumen de inversión dedicado a este tipo de comunicación podría ser mayor, si no fuera por un factor muy importante, como son los bajos precios de los espacios publicitarios que la televisión comercializa.

En el caso de los medios de vía pública una mejor tecnología en el material de los paneles logra darle a los mensajes mayor impacto y renovados elementos, como paraderos, paletas, cabinas, etcétera, acercan el mensaje al transeúnte, logrando una comunicación más directa y eficaz; así, las inversiones en este medio han crecido en 330 por ciento respecto del año 1995.

Con el cable ha sucedido un efecto similar; comparando el primer registro oficial de 1998 con el último del 2004 el incremento es de 300 por ciento, lo cual grafica el interés por un medio mucho más segmentado que la televisión abierta.

Dentro del rubro "otros" del cuadro de inversiones se incluyen: correo directo (encartes), internet, cine y publicidad en buses. El incremento ha sido de 110 por ciento en el periodo 19952004. Prácticamente el 50 por ciento de esta cantidad se encuentra en correo directo.

Se manejan otras actividades publicitarias no incluidas en el cuadro de inversiones por carecer de información, pero que se encuentran en franca expansión, como es el márketing promocional y está relacionado con una serie de acciones que buscan llegar directamente al usuario, a través 
de diversos eventos realizados en ambientes públicos, como restaurantes, discotecas, playas, etcétera.

Respecto de la evolución de las inversiones en los medios masivos, la radio y las revistas han mantenido su participación por ser medios más segmentados. La gran cantidad de vehículos que presenta cada uno de ellos propició la necesidad de especializar sus contenidos. En el caso de los diarios, se observa una caída de su inversión en estos últimos años que representa una pérdida del 8 por ciento de su inversión entre el 2001 y el 2004, mientras en estos mismos años se fortalecen los medios no masivos.

La televisión presenta una caída muy fuerte (-37 por ciento) en los últimos diez años. Es la conjunción de varios factores, por un lado, la inclusión de otros medios - no masivos- en los rígidos presupuestos publicitarios a costa de otros medios, especialmente la televisión, por ser el medio eje de la mayoría de las campañas masivas. De otra parte, este medio enfrentó problemas de índole político-económica que desestabilizaron la administración de las empresas, encontrándose aún en etapa de recuperación.

En resumen, el panorama presenta una pérdida de la eficacia publicitaria de los medios masivos versus un auge de medios que llegan a públicos más segmentados, tratando de promover una respuesta directa del consumidor.

Los medios masivos, especialmente los electrónicos, están próximos a enfrentar cambios radicales en su presentación dentro de una era digitalizada; estos aspectos van a cambiar los conceptos en el manejo de las campañas publicitarias, en donde los mismos actores del mercado publicitario no saben qué decisiones tomarán. 